\title{
Teachers for "Smart Classrooms": The Extent of Implementation of an Interactive Whiteboard- based Professional Development Program on Elementary Teachers' Instructional Practices
}

\author{
Ina Blau \\ Open University of Israel, Ra'anana, Israel \\ inabl@openu.ac.il
}

\begin{abstract}
This study investigates the implementation of an Interactive Whiteboard (IWB) professional development program on instructional practices of elementary teachers. The research assesses to what extent teachers implement IWB-related strategies (e.g., technology-pedagogy correspondence, interactivity types, teaching-learning mode, differentiated learning, student-centered learning, multimedia principles, and appropriate design of IWB slides) in their instructional practices after completion of a 30 -hour IWB professional development program. A case study design was used. The data was collected immediately after the course using the instrument for assessing IWB lessons through non-participant observations of 43 elementary teachers coming from different subject-matters and schools. The results are discussed in terms of constructivist and cognitive approaches to teaching and learning. Consistent with the constructivist pedagogy, teachers encouraged IBW-student interactions; however, they did not stimulate enough student-student communication. They adapted non-linear learning techniques across the Internet; however, they continued the linear use of prepared IWB files. The lessons' time was divided between the whole class teaching $(50 \%)$ and more differentiated individual or small group activities. The teachers functioned more as "guide on the side", scaffolding student learning, rather than transferring knowledge. Regarding the cognitive approach, the participants' abilities to apply the multimedia principles and the level of their digital design skills were very high. IWB programs should promote interactivity among students, emphasize saving IBW files for further review, and using nonlinear learning through IBW files.
\end{abstract}

Keywords: interactive whiteboard - IWB, Smart classroom, instrument for assessing IWB lessons, technology implementation at schools, teacher professional development program.

Material published as part of this publication, either on-line or in print, is copyrighted by the Informing Science Institute. Permission to make digital or paper copy of part or all of these works for personal or classroom use is granted without fee provided that the copies are not made or distributed for profit or commercial advantage AND that copies 1) bear this notice in full and 2) give the full citation on the first page. It is permissible to abstract these works so long as credit is given. To copy in all other cases or to republish or to post on a server or to redistribute to lists requires specific permission and payment of a fee. Contact Publisher@InformingScience.org to request redistribution permission.

\section{Introduction}

The Israeli education system began a reform towards comprehensive integration of ICT technologies in order to develop and enhance students' $21^{\text {st }}$ century skills. As a part of this process, some elementary and high schools implement Interactive Whiteboards (IWB) in the classrooms. In some cases IWB are do-

\section{Editor: Alex Koohang}

An earlier, shorter version of this paper was presented at the Chais conference 2011, in Raanana, Israel, and included in Y. Eshet-Alkalai, A. Caspi, S. Eden, N. Geri, \& Y. Yair (Eds.), Proceedings of the Chais conference on instructional technologies research 2011: Learning in the technological era. Raanana: The Open University of Israel. http://www.openu.ac.il/research center/chais2011/papers.html 
nated to schools in periphery; in others they are purchased by municipal authorities or by schools themselves. The process of technology implementation is accompanied by teacher professional development for smart use of the possibilities offered by a "smart classroom." The integration of IWBs in elementary schools has the potential to have a significant impact on pedagogy (Way et al., 2009). There are two important factors affecting the implementation of this technology: what features of the IWB teachers choose to use and how they choose to use them.

This study investigates the implementation of an IWB professional development program on instructional practices of elementary school teachers. After completion of a 30-hour professional development program, the study assesses to what extent elementary teachers are observed to implement IWB-related strategies (e.g., technology-pedagogy correspondence, interactivity types, teaching-learning mode, student-centered learning, differentiated learning, multimedia instructional message, and appropriate design of IWB slides) in their instructional practices.

\section{Conceptual Frameworks}

This study is based on two major conceptual frameworks. The first is the constructivist approach to teaching and learning, according to which IBW lessons should (a) encourage interactive learning, (b) use the technology as a 'mindtool' (Jonassen, 2006) for extending students' cognition and supporting knowledge construction, and (c) include non-linear learning in order to promote the development of high-order skills and flexible and creative thinking. The second framework is the cognitive approach to teaching and learning, based on which IBW lessons should (a) include multimedia instruction (i.e., combined visuals and verbal messages) for building effective multiple memory representations and reducing cognitive load during the learning process, and (b) use digital design principles matching the perception of students. These aspects are discussed in the next sections.

\section{Interactive Learning through IBW}

The important question raised in the literature is related to the definition of interactivity through IWB: "Is it the board that is interactive and/or does the way the teacher use the board in their lesson influence the level of interactivity with the learning?" (Shenton \& Pagett, 2007, p. 130). According to these researchers, if teachers use IWB technology to present some software or Internet resources, their lessons automatically become more interactive. Others hold that lesson interactivity refers to the teaching method in which the lesson is conducted and not by what the IWB presents (Kennewell, 2006; Knight, Pennant, \& Piggott, 2004). According to Knight et al., we need to distinguish between the pedagogical interactivity of teaching and learning (teacher-students interactions as well as interactions of students with their peers) and technical interactivity (i.e., physical interaction with the device). However, the same term is used for essentially different technical interactivity by the teacher presenting external / internal IWB resources (Beauchamp \& Parkinson, 2005; Shenton \& Pagett, 2007) versus technical interactivity by students interacting with these learning resources through IWB (Knight et al., 2004). IWB-teacher interactivity is quite an obvious form of interaction not only for IWB, but also for teaching with an ordinal projector, while for IWB-students interactivity teacher awareness of its importance is needed. Pedagogical interactivity, in turn, can be defined in two ways: (1) as interactive teaching, in which "students contributions are encouraged, expected and extended" (Kennewell, Tanner, Jones, \& Beauchamp, 2008, p. 62), i.e., teacher-students interactivity, and (2) as "engaging students, student practical and active involvement, collaborative activity, and conveying knowledge" (Wood \& Ashfield, 2008, p. 86), i.e., interactivity among peers. Both definitions of pedagogical interactivity are essential from a socio-constructivist learning perspective for promoting immediate developmental progress of students (Vygotsky, 1978), imply a deep level of participation by 
students and a degree of student control that is considered valuable for understanding concepts and developing higher-order thinking skills (Kennewell et. al, 2008).

Beauchamp and Parkinson (2005) present the combination of pedagogical and technical interactivity, believing that both the choice of information displayed, as well as the style in which the lesson is presented, play an important role in interactions through IBW technology. Technical interactivity can stimulate practice of skills, while pedagogical interactivity supports higher-order thinking and reflections on the learning process (Kennewell et al., 2008).

The types of interactivity investigated in this study include (1) pedagogical interactivity between teacher and learners, (2) pedagogical interactivity among learners themselves, and (3) technical interactivity of learners with the IWB, i.e., learners interacting with learning content through technology (but not technical interactivity by teacher presenting resources through IWB, which can be seen as byproduct of using this technology).

\section{Non-linear Learning: Hypertext and Hypermedia through IWB}

Non-linear learning has a potential to promote the development of high-order skills as well as flexible and creative thinking among students. Spiro and his colleagues (Spiro, Feltovich, Jacobson, \& Coulson, 1992, 1995) proposed the Cognitive Flexibility Theory (CFT) that applies to the transfer of basic abstract concepts to naturally occurring situations in domains otherwise perceived as well-structured. The Cognitive Flexibility Hypertexts (CFHs) are non-linear computer learning environments linking text/media that enhance cognitive flexibility by allowing learners to visit the same material at different times and in rearranged contexts, to serve multiple purposes and conceptual perspectives (Spiro, Coulson, Feltovich, \& Anderson, 1988; Spiro \& Jehng, 1990). The results of experimental research converge toward the conclusion (Cernusca, 2007) that compared to traditional textbooks, CFH scaffolds and provides a significantly better transfer of learning for complex tasks such as problem solving, analysis, or synthesis. Implementation and examination of CFH among undergraduates in Cernusca's study found a consistent significant increase of students' performance outcome mean scores when the CFH was a part of the instructional process. Both CFT and the pedagogical model of CFH can be successfully used for professional development in higher education (Simpson, 2006). When novice and experienced adjunct instructors in her study gained familiarity with active learning strategies as they participated in the training, they embraced it and moved beyond active learning pedagogy with their students. Despite this potential of non-linear learning environments promoting the learning process and successful training for its implementation described by the literature, previous studies did not explore the implementation of non-linear teaching and learning with IWB.

IWB support non-linear learning in two main ways: (1) by accessing hypertext and hypermedia to online content or external computer files and (2) by moving back and forth within the IBW file for review slides related to questions or answers of the students (Blau, 2011). The guidance offered by IBW file reduces navigational frustrations of random access hypertexts and hypermedia. In addition, it can help students to create multiple schemas as they move from one case to another that has a similar instance of the same conceptual structure.

\section{IWB as a Mindtool}

There have been some fervent claims made by policy-makers that the IWB has the potential to 'revolutionize' pedagogical practice (Gillen, Starrman, Littleton, Mercer \& Twiner, 2008). The analysis of IWB activities during math and English lessons (Kennewell \& Beauchamp, 2007) showed activities that are more effective with IBW compared to black/whiteboard and functions that are possible only with IWB (e.g., results of math questions saved for review on the next lesson). In some advanced cases, especially when student-IWB interactivity is involved, this tech- 
nology is used as a 'mindtool' (Jonassen, 2006) extending students' cognition and supporting the thinking process. According to Jonassen, using technology as a mindtool is a student-centered process encouraging knowledge construction by students and promoting the constructivist approach to teaching and learning. However, in some cases the use of the IWB appeared to be simply replacing the blackboard. The literature expressed concern about 'misuse' of IWB by teachers by over-using functions that simply mimic chalkboard techniques, primarily writing, with a lowlevel of student engagement (Kennewell \& Beauchamp, 2007; Way et al., 2009).

This study investigated whether teachers use IWB functions (e.g., give a group of students capturing results of simulation and building a diagram based on them) that promote student-centered learning process, scaffolding, and moderating student thinking and knowledge construction.

\section{Multimedia Learning through IWB}

From the cognitive perspective to teaching and learning, the undisputed point of IWB impact is that attention and engagement of almost all children are stimulated by the multimedia affordances delivered by the IWB (Way et al., 2009). According to the Cognitive Theory of Multimedia (Mayer, 2001), explanations including multiple representations (i.e., both visual and verbal messages) are more effective compared to the explanations based solely on visual or verbal representations. The author explains this effectiveness by building two different mental representations, i.e., the visual mental model and the verbal one, as well as by building multiple connections between them in the memory.

In addition to this general multiple representation principle, Mayer and Moreno (2003) and Moreno and Mayer (2007) presented some specific recommendations for conveying multimedia instructional messages and diminishing the cognitive load. According to the contiguity principle, multimedia messages should present visual and verbal messages contiguously rather than separately because corresponding pictures and words must be co-located in working memory in order to facilitate the construction of referential links between them. Thus, for learning content with narration synchronous delivery is recommended: listening to a narration while also viewing corresponding animation is more effective than listening to the narration before or after viewing the animation. For captioned illustrations the nearness of illustrations and text is recommended: figures placed near the related text explanations are more effective than figures and text explanations distant from each other. According to the split-attention principle, presenting verbal information as auditory narration is preferable to on-slide text because the visual processing system can be overload by processing both animation and on-slide text. In contrast to written text, auditory narration is processed by the verbal information processing system parallel to the processing of animation by the visual system. Thus, teachers should give oral explanations rather than write them on IWB slides. In addition, teachers should not write the explanations on the slide for reading them aloud on the lesson - this strategy was found as ineffective for giving explanations. Therefore, reading text aloud from IWB slides needs to be limited to the special cases when the reading is used as a teaching method and has an added value for learning, (e.g., during reading acquisition, studying text in foreign language, understanding definitions or citations).

This study assesses both the general use of multimedia representations combining visual and verbal messages (Mayer, 2001), as well as specific forms of applying multimedia principles discussed by Mayer and Moreno (2003) and Moreno and Mayer (2007) on teaching with IBW.

\section{Design of IWB Slides}

From the cognitive perspective, appropriate design of digital learning materials and environments should correspond to student perception. Analyzing the design of IWB slides, this study used Eshet and Hammer's (2005) implications of Gestalt perception principles - figure and ground, 
closure, proximity, similarity, and continuity - for designing digital environments. According to the figure and ground principle, in digital design it is important to keep the figure (e.g., text or objects) contrasting to the ground of the slide. The implications for the closure, proximity, and similarity principles refer to the arrangement of text and objects on the slide. Thus, semantically similar objects (e.g., parts of a diagram with related content) should be arranged in proximity and encoded by the same color or/and the same geometric figure, while a distinct group of objects should be placed separately from the first group, have font/form/filling color contrasting to the first group of objects as well as another geometric figure. The implication for the continuity principle is a similar design of different IWB slides which conveying the feel of completeness to the audience.

\section{Research Question}

This study investigates the implementation of an IWB professional development program on instructional practices of elementary teachers. After completion of a 30-hour IWB professional development program, to what extent are elementary teachers observed to implement IWB-related strategies in their instructional practices (e.g., technology-pedagogy correspondence, interactivity types, teaching-learning mode, differentiated learning, student-centered learning, multimedia instruction, and appropriate design of IWB slides)?

\section{Method}

\section{Participants}

Participants were 43 teachers working in variety of elementary schools in the North of Israel. The age range was 28-53; six of the participants were men (14\%). Gender representations in the sample correspond to gender distribution among elementary school teachers in Israel. The participants teach a variety of subject-matters: math, Hebrew (native language), English (foreign language), science, special education, history, geography, bible, technology, art, and physical education. The experience in teaching ranged from 2 to 25 years. General ICT skills varied significantly between the participants; however all of them were inexperienced in teaching with IWB.

\section{Professional Development IWB Program}

During the spring-summer of 2010 all of the participants finished a standard 30 hour course of professional development towards implementing IWB in their classroom. Elementary teachers in the Israeli educational system complete 60 hours of professional development per year and receive a salary increment after finishing their training. Sometimes teachers can freely choose the courses; in other cases, professional development programs are recommended by school principals according to the school agenda and even obligatory - as a result of educational reforms or implementation of new curriculum. The program assessed in this study was not obligatory. Anticipating the installation of IWB donated to their schools or purchased by municipal authorities and schools themselves, most of the teachers came to training by their own choice; some of the teachers came following the recommendation of their school principals.

The participants of this study learned in three groups trained by the same instructor, in one center of professional development, during the same period of time, using the same IWB program, syllabus, and website with learning materials. Since the course included pedagogical models, technological components of use the IWB program, and the experience of instruction with IWB, the training was carried out in groups of up to 15 teachers.

According to the standard procedure of professional development, the instructor for this course and the syllabus of the IWB program were approved by the Ministry of Education supervision. 
The instructor holds a MA degree in education and has experience in ICT training and teacher mentoring. The program emphasized the correspondence of technological tools with teacher instructional goals, promoted pedagogical and technical interactivity, and combined different teaching-learning modes, such as drill and practice, knowledge transmission, or knowledge construction. The course embraced student-centered learning, scaffold and moderated by the instructor. Lessons were divided between whole-class activities, such as explanations, demonstrations, and discussions, as well as differentiated individual practice and learning in small groups. The importance of using multimedia instruction in IWB lessons was explained and the appropriate design of IWB slides was demonstrated and practiced. Finally, the participants practiced assessing teaching with IWB using the instrument of this study and, therefore, were familiar with its components.

\section{Instrumentation}

This study used the instrument for assessing teaching with IWB (Blau, 2011). Content validity of the instrument was checked by two ICT experts. The reliability of the instrument was checked during the pilot by 3 judges trained by the researcher and between-rater agreement coefficient was Kendall's $W=.78$.

The assessment instrument includes 7 parts:

1. Technology-pedagogy correspondence was assessed on a scale from $1=$ not at all to $5=$ very much. This part includes six evaluations: the extent of matching technological tools with pedagogical goals (e.g., choosing drill simulations for practicing skills, symbolic simulations presenting processes - for knowledge transmission, and experimental simulations actively involving students in learning by doing - for knowledge construction), using special IBW functions (e.g., screen capturing, highlighting, gradual screen exposure, IBW learning objects) using IBW file as a learning content management system- LCMS, saving IBW files for further review, practicing non-linear learning through IBW file (i.e., moving back and forth within the IBW file), and non-linear learning across the Internet (i.e., moving back and forth from IBW file to online hypertext or hypermedia resources and vice versa).

2. Interactivity was measured on a scale from $1=$ not at all to $5=$ very much. Three types of interactivity were evaluated: pedagogical interactivity between teacher and students, pedagogical interactivity among students, and technical interactivity between students and IBW (e.g., students interacting with learning resources through IWB).

3. Teaching-learning mode was measured as the perceived by a judge percentage of lesson time dedicated to drill and practice activities, knowledge transmission by teacher or technology, and knowledge construction by students.

4. Differentiated learning was measured as the perceived by a judge percentage of lesson time dedicated to individual learning, learning in small groups, and whole-class activities.

5. The role of teacher was measured as the perceived by a judge percentage of lesson time dedicated to teacher-centered instruction with a teacher as a principal knowledge source versus the percentage of time for student-centered learning, scaffold and moderated by the teacher.

6. Multimedia principle (Mayer, 2001) and its implications for instructional design (Mayer $\&$ Moreno, 2003; Moreno \& Mayer, 2007) were measured on a scale $1=$ not at all, $2=$ low, 3 = medium, 4 = high, including "irrelevant" option. This part includes five evaluations: the general extent of using multiple (i.e., visual and verbal) representations, and four specific evaluations - the extent of using auditory narration (either by technology, e.g., video clip, or explained by teacher) rather than written text, placing the text near cor- 
responding parts of the figures in captioned illustrations, avoiding reading aloud written explanations from the IWB slide, and synchronizing visual presentation with verbal explanation instead of explaining the visual information (e.g., simulation) before or after showing it to students.

7. Appropriate design of IWB slides was measured on a scale $1=$ not at all, $2=$ low, $3=$ medium, 4 = high, including "irrelevant" option. The implications of the Gestalt perception principles - figure and ground contrast, closure, proximity, similarity, and continuity - were used for evaluating digital design of IWB slides (based on Eshet \& Hammer, 2005). This part includes six evaluations: to what extend the IBW slides keep the contrast between figure (e.g., text or objects) and the ground of the slide, text and objects are appropriately arranged on the slides, semantically similar objects are placed in proximity as well as encoded by the same color and geometric figure, the design of the slides is similar producing the feel of completeness, and the size of text fonts and objects on the slides is appropriate.

\section{Data Collection}

This research used a case study design assessing the lessons prepared, presented, and published online in a course website by the 43 participants immediately after finishing the IWB professional development program. The teachers were informed regarding the observations. Each participant was free in choosing the format and the content of her or his lesson. All the lessons were analyzed using the instrument developed for assessing teaching with IWB presented above. The data was collected through non-participant observations. Twenty five percent of the lessons were assessed by a second judge and the inter-rater reliability was high, Cohen's $\kappa=.83$.

\section{Results}

\section{Technology-Pedagogy Correspondence}

Figure 1 showed the average level of correspondence of the technological tools chosen by the participants for their pedagogical purposes.

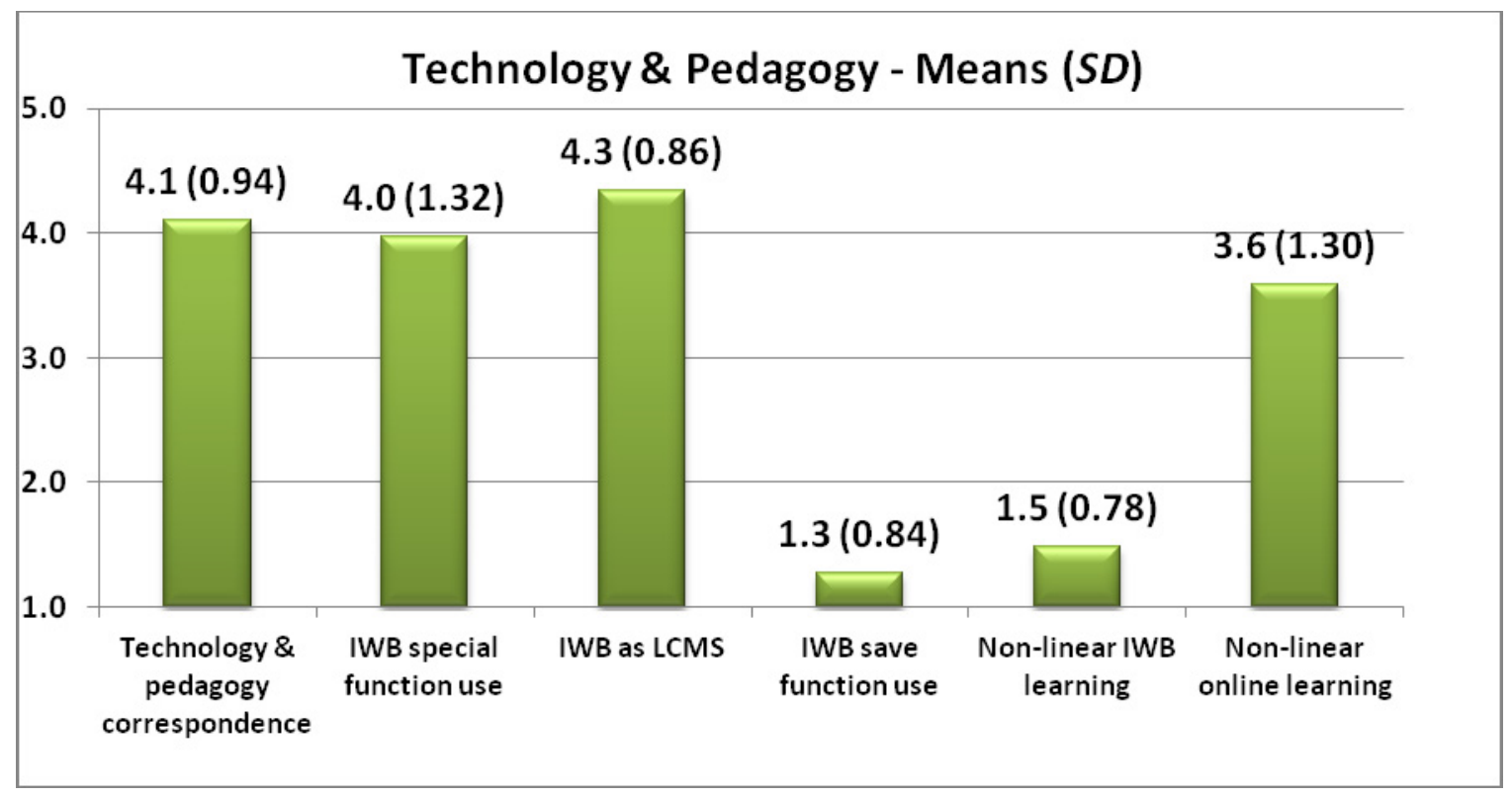

Figure 1: Technology-pedagogy correspondence in participant lessons: Means and $S D$ 
As can be seen from Figure 1, on average, the participants chose an appropriate technological tool for their pedagogical goals. They used a variety of functions special to IWB technology beyond the options of an ordinal projector. Most of the participants used the IWB files as LCMS which include all learning recourses, links, and external files prepared for class activities before the lesson. However, the participants rarely used the save function, opening the possibility for latter reviews of the content as well as publishing it on the class website and essential for IWB technology. The analysis also showed different use of non-linear learning types in the lessons presented: while the participants widely used external links to Internet resources and other files on their computer, they rarely used non-linear learning within the IWB files, moving back and forth for review other IWB slides related to questions or comments of their students.

\section{Interactivity Types}

Figure 2 presents the average evaluations for different types of pedagogical and technical interactivity showed in the lessons of the participants.

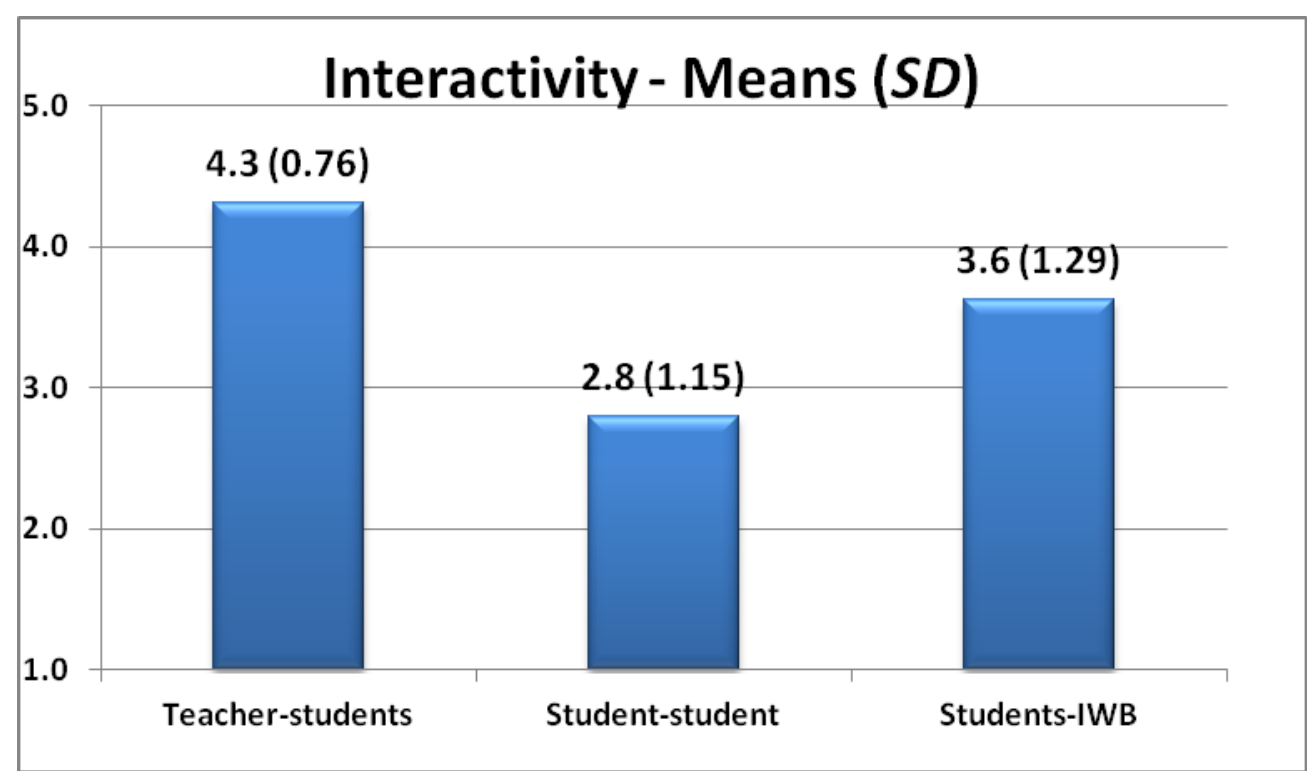

Figure 2: Interactivity types: Means and $S D$

As can be seen from the results presented by Figure 2, there was a high level of pedagogical interactivity as teacher-students interactions, and a satisfactory level of technological interactivity as students' interactions with learning resources through IWB. However, the level of pedagogical interactivity among students was below the average.

\section{Teaching-Learning Modes}

Figure 3 shows the average ratio of the time dedicated to different teaching-learning modes in the participant lessons. 


\section{Teaching-Learning Mode Ratio}

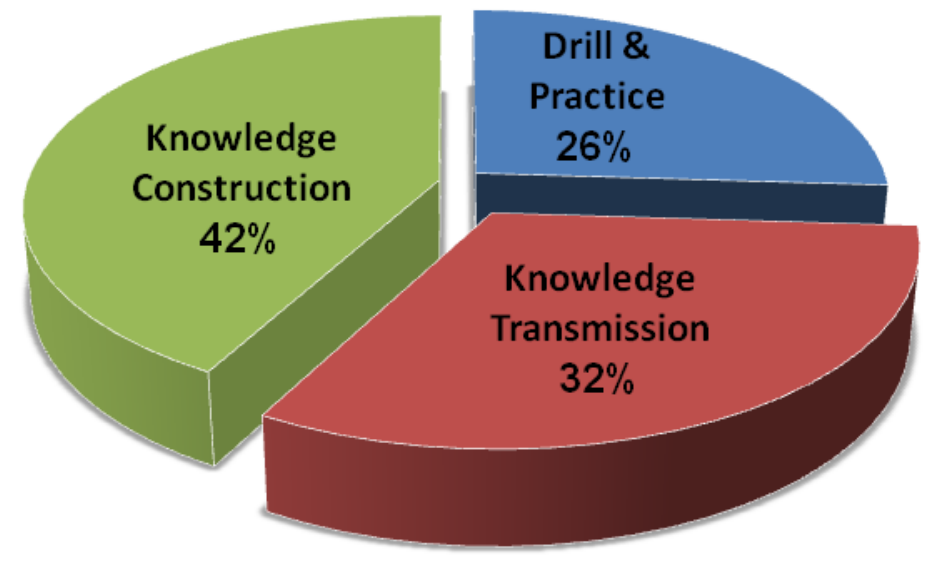

Figure 3: Average teaching-learning mode ratio

As Figure 3 presents, on average, the participants widely used traditional teaching-learning modes, i.e., drill and practice activities and knowledge transmission from teacher or from technological resources to students. However, $42 \%$ of time in the participant lessons was dedicated to activities supported knowledge construction by learners.

\section{Differentiated Learning}

Figure 4 presents the average ratio of the lesson time dedicated by the participants to differentiated individual learning and learning in small groups versus whole-class teaching.

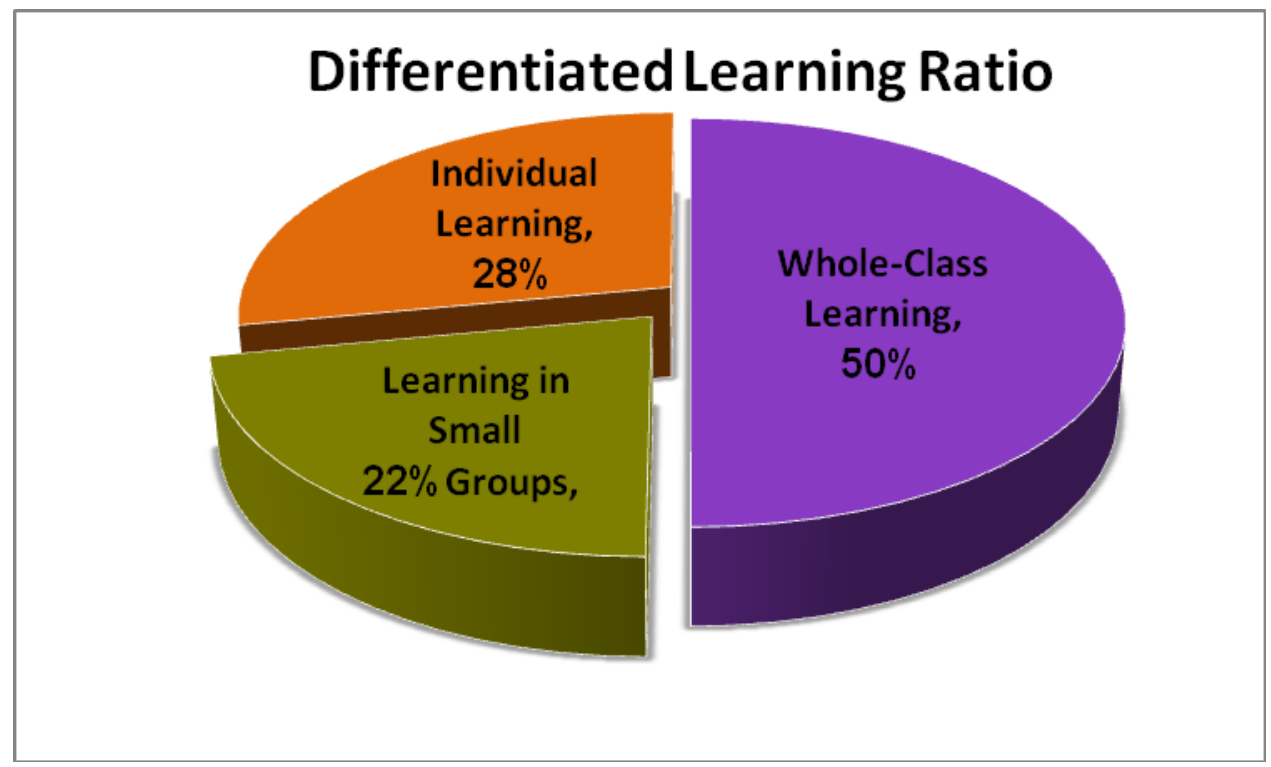

Figure 4: Average ratio of individual and small-groups learning versus whole-class activities

As can be seen, in average, time in the participant lessons was equally divided between the whole-class activities and differentiated learning. However, slightly more time was dedicated to individual learning rather than to learning in small groups. 


\section{The Role of Teacher}

Analyzing the role of teacher in the lessons presented revealed that in average $42.7 \%$ of the time the participants adapt teacher-centered instruction with a teacher as a principal source of knowledge. However, $57.3 \%$ of the lesson time was dedicated to student-centered learning process, scaffold and moderated by the teacher.

\section{Multimedia Learning}

Figure 5 shows the means and standard deviations of multimedia instructional messages delivery in the lessons of the study participants.

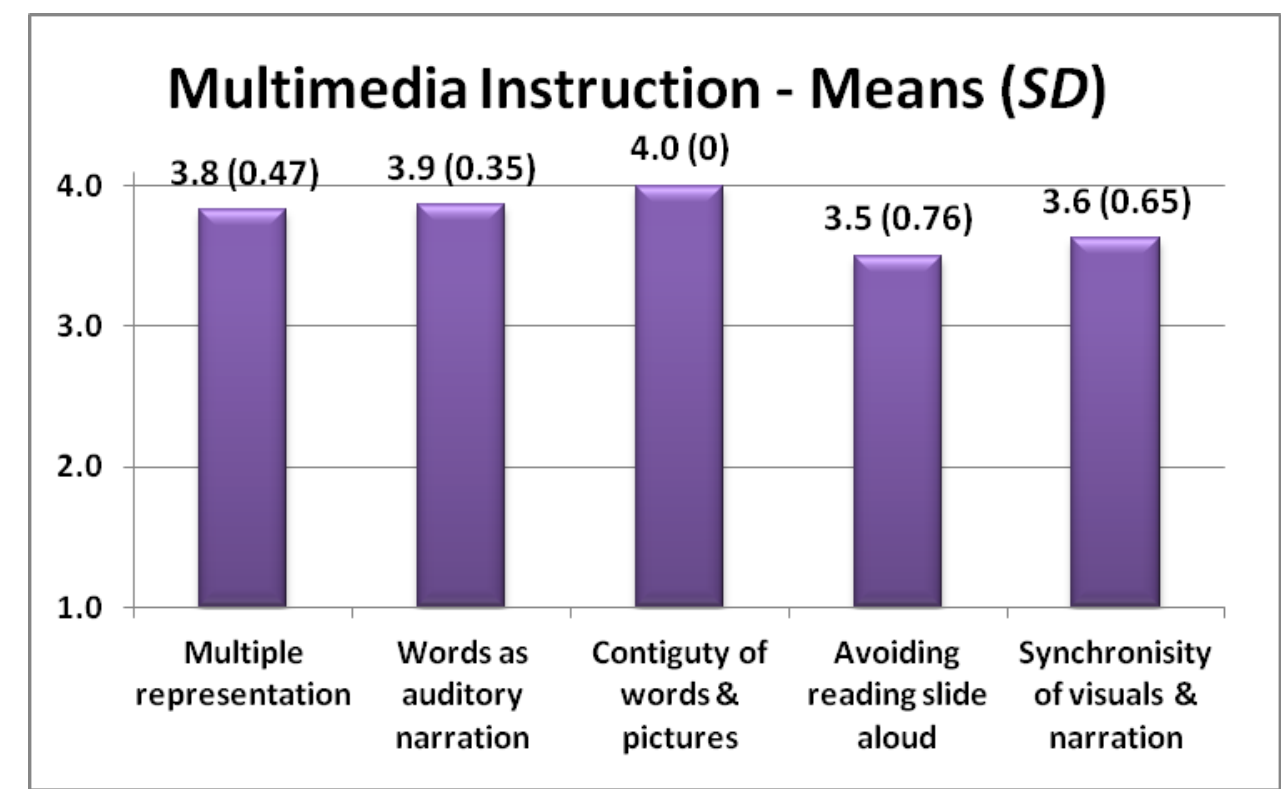

Figure 5: Conveying multimedia instructional messages through IBW: Means and $S D$

As can be seen from Figure 5, the participants understood the effectiveness of multimedia learning and highly used multiple visual and verbal representations. They also widely used auditory narration, either by technology (e.g., video clip, computer simulation with oral explanation) or explaining by themselves, instead of presenting information as written text on the IWB slides. Presenting captioned illustrations, participants placed the text near corresponding parts of the figures. Except for reading phrases in foreign languages and citations from the Bible, the participants preferred giving oral explanations instead of writing explanations on the IWB slide and reading them aloud. Verbal explanations were synchronized with related visual presentations.

\section{IWB Slides Design}

Figure 6 shows the analysis of IWB slides' design. As was mentioned before, this analysis was based on implications of the Gestalt perception principles - figure and ground contrast, closure, proximity, similarity, and continuity - on the design of digital environments (based on Eshet \& Hammer, 2005). 


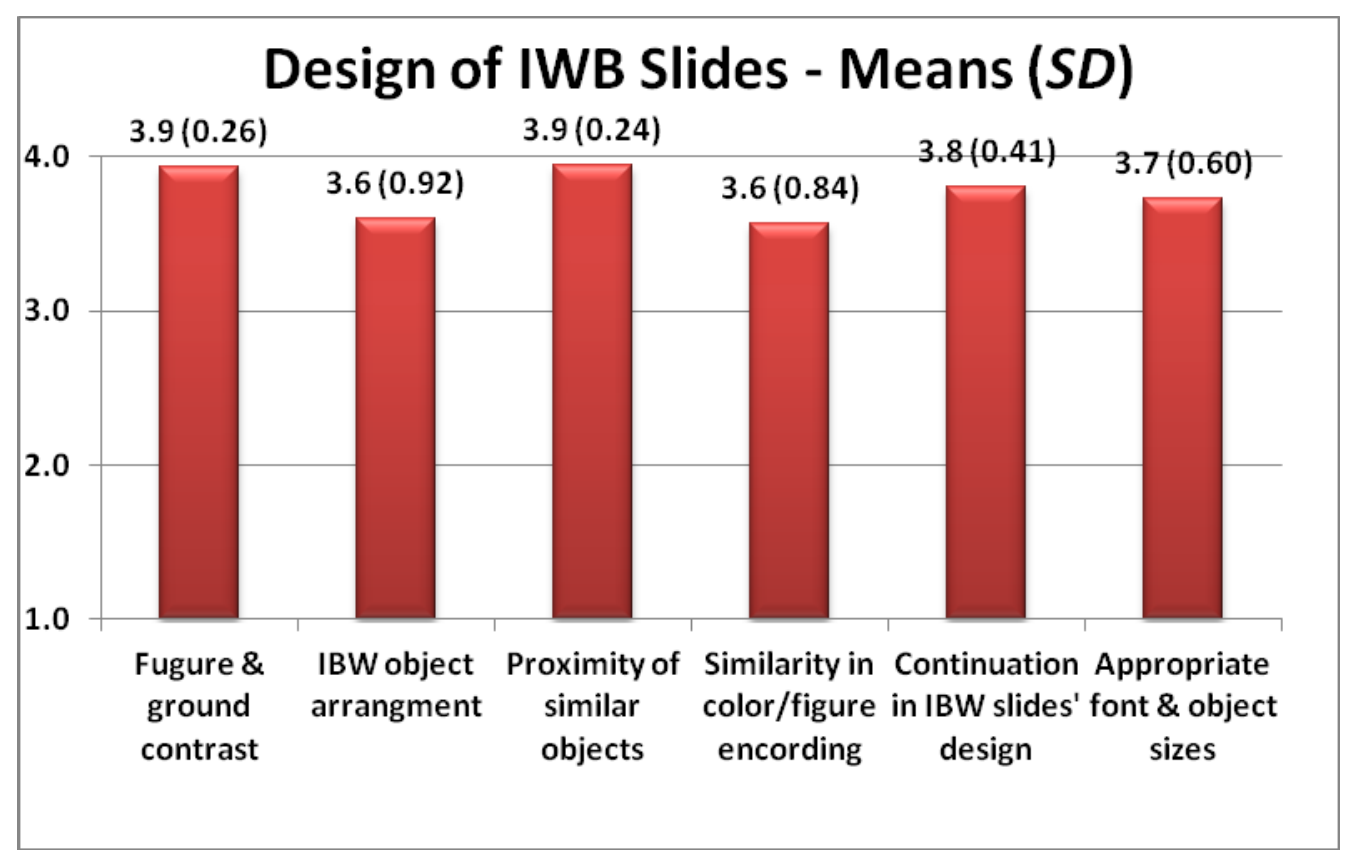

Figure 6: Design of IWB slides: Means and $S D$

As Figure 6 presents, on average, the study participants kept the contrast between figures - text or objects - and the ground of the IWB slide. The arrangement of text and objects on the slides was appropriate: semantically similar objects were place in proximity and encoded by the same color and geometric figure. A similarity in the design of the slides produced the feel of completeness. Most of the participants chose an appropriate size of text fonts and objects on the slides.

\section{Discussion and Conclusion}

This study investigated the implementation of an IWB professional development program on instructional practices of elementary teachers. After completion of a 30-hour professional development program, the study assessed to what extent elementary teachers are observed to implement IWB-related strategies (e.g., technology-pedagogy correspondence, interactivity types, teachinglearning mode, differentiated learning, student-centered learning, multimedia instruction, and appropriate design of IWB slides) in their instructional practices. This section is organized according to two major conceptual frameworks of this study: first the results are discussed based on the constructivist approach following by the discussion from the cognitive perspective to teaching and learning.

Consistent with the constructivist paradigm and especially with socio-constructivist approach (Vygotsky, 1978), pedagogical interactivity appears to be most significant for effective learning with IWB (Kennewell et al., 2008). The level of the pedagogical interactivity between teacher and students in the lessons presented by the participants of this study was high; however, the pedagogical interactivity among students was slightly below the average. It seems that the relatively small amount of time dedicated to small-group learning can explain this finding. Pedagogical interactivity among learners implies a high level of student participation and a degree of student controlling their learning that is considered valuable for understanding concepts and developing higher-order skills (Kennewell et. al, 2008). Therefore, emphasizing this interaction type during the courses for teacher professional development and the work of educational consultants in schools implementing IWB is recommended. 
"The most effective use of IWBs seems... likely to involve striking a balance between providing a clear structure for a well-resourced lesson and retaining the capacity for more spontaneous or provisional adaptation of the lesson as it proceeds" (Gillen et al., 2008, p.254). Non-linear learning by IWB provides both a structure by accessing hypertext and hypermedia to online content or external computer files and the capacity of adaptation and change to the lesson planned by moving back and forth inside the IWB file. However, the results showed that the participants mostly based non-linear learning in their lessons on links to Internet resources and ignored the possibility of non-linear learning within the IWB files. Moving back and forth within the IWB file for review slides or changing the lesson plan according to students' questions or answers as the lesson proceeds can enhance cognitive flexibility by allowing learners to visit the same material at different times and in rearranged contexts, to serve multiple purposes and conceptual perspectives. Therefore it should be emphasized during the training for IWB implementation.

Concerning the differentiated learning, study of IWB integration in the UK reported that lessons with IWB are more often dominated by whole-class activities (Smith, Hardman, \& Higgins, 2006). Categorizing IWB technology, some authors even use the term "interactive whole-class technologies" (IWCTs) (Beauchamp et al., 2010). In the current study, the participants differentiated the learning process and only the half of the lesson time was dedicated to whole-class learning. Nonetheless, the participants slightly preferred individual learning to activities in smallgroups. As mentioned above, most of the opportunities for the pedagogical interactivity among students happened in small-group learning. Thus, the rare use of learning in small groups can explain the relatively low level of pedagogical interactivity among learners found in this study. According to the socio-constructivist approach, learning in small groups is essential to promote student immediate progress within a Zone of Proximal Development - the gap between the actual developmental level of a student as determined by independent learning and the level of potential development through learning in collaboration with more capable peer (Vygotsky, 1978). Therefore, encouraging differentiated learning in small groups during the professional development program and emphasizing its importance for further teaching and learning in "smart classroom" is recommended.

The literature presents conflicting findings regarding the role of teacher in "smart classroom" (Hennessy, Deaney, Ruthven, \& Winterbottom, 2007). The major concern is that IWB technology mostly promotes teacher-centered pedagogical approach with low-level of student active participation (Way et al., 2009). The results of this study does not support the concern: most of the time the study participants did not function as the main source of knowledge for their students; instead, they moderated student-centered learning, functioned more as "guide on the side" scaffolding student learning, rather than transferring knowledge. The participants combined pedagogical approaches, widely using constructivist activities. This result is consistent with the literature (Beauchamp et al., 2010; Becker \& Lee, 2009; Higgins, Beauchamp \& Miller, 2007; Way et al., 2009), reporting the notion of the IWB as being a potential catalyst for pedagogical shift; however, the conscious and willing effort of the teacher is required for a 'shift in power' to take effect.

Regarding the cognitive approach to teaching and learning with technology, it is highlighted in the literature that the multimodal nature of IWB resources is engaging students through dynamic multimedia learning, combining visual and verbal representation of content (Gillen et al., 2008; Kennewell \& Beauchamp, 2007). This study showed that training teachers for effective delivering of multimedia instruction leads to the successful implementation of the principles learned during the program in the lessons presented by the participants. Similarly, the findings concerning the appropriate digital design of IWB slides were very satisfactory. There is a shortage of the research explored teaching and learning with IWB based on the cognitive approach in general and multimedia instruction and digital design in particular. The delivery of multimedia instructional 
messages using IWB and digital design of IWB slides have important implication for education and need more empirical investigations.

To conclude, after the course of professional development, the results showed a high level of implementing the principals learned and practiced during the training into the instructional practices of elementary teachers. The analysis of the lessons revealed a matching between the chosen technological tools and the pedagogical goals. The teachers encouraged IBW-student interactions; however, they did not stimulate enough student-student communication. They adapted non-linear learning techniques across the Internet; however, they continued the linear use of prepared IWB

files. The lessons' time was divided between the whole class teaching $(50 \%)$ and more differentiated individual or small group activities. The teachers functioned more as "guide on the side", scaffolding student learning, rather than transferring knowledge. The participants' abilities to deliver multimedia instructional messages and the level of their digital design skills were very high.

It should be kept in mind, however, that this study focused on the implementation of an IWB professional development program on instructional practices of elementary teachers and analyzed lessons presented by teachers immediately after the professional development course. We recommend future long-term investigations that continue testing of these constructivist and cognitive components of teaching and learning in a "smart classroom".

\section{References}

Beauchamp, G., Kennewell, S., Tanner, H., \& Jones, S. (2010). Interactive whiteboards and all that jazz: The contribution of musical metaphors to the analysis of classroom activity with interactive technologies. Technology, Pedagogy and Education, 19, 143-157.

Beauchamp, G., \& Parkinson, J. (2005). Beyond the 'wow' factor: Developing interactivity with the interactive whiteboard. School Science Review, 86, 97-103.

Becker, C., \& Lee, M. (2009). The interactive whiteboard revolution: Teaching with IWBs. Victoria, Australia: ACER Press.

Blau, I. (2011). Being a smart teacher in a "Smart classroom": Assessing teacher professional development for incorporating Interactive WhiteBoards at schools. In Y. Eshet-Alkalai, A. Caspi, \& S. Eden (Eds.), Learning in the Technological Era (pp. 63-74). Ra'anana, Israel: Open University of Israel. [in Hebrew].

Cernusca, D. (2007). A design-based research approach to the implementation and examination of a cognitive flexibility hypertext in a large undergraduate course. $\mathrm{PhD}$ Thesis. Information science and learning technologies, University of Missouri, Columbia.

Eshet, Y., \& Hammer, R. (2005). Principles of design and analysis of computer-based learning environments. Ra'anana: Open University of Israel. [in Hebrew]

Gillen, J., Staarman, J., Littleton, K., Mercer, N., \& Twiner, A. (2008). A 'learning revolution'? Investigating pedagogic practice around interactive whiteboards in British primary classrooms. Learning Media and Technology, 32, 243-256.

Hennessy, S., Deaney, R., Ruthven, K., \& Winterbottom, M. (2007). Pedagogical strategies for using the interactive whiteboard to foster learner participation in school science. Learning, Media, and Technology, 32, 283-301.

Higgins, S., Beauchamp, G., \& Miller, D. (2007). Reviewing the literature on interactive whiteboards. Learning, Media and Technology, 32, 213-225.

Jonassen, D. H. (2006). Modeling with technology: Mindtools for conceptual change ( $3^{\text {rd }}$ ed.). Upper Saddle River, NJ: Prentice-Hall. 
Kennewell, S. (2006). Reflections on the interactive whiteboard phenomenon: A synthesis of research from the UK. Paper presented at the AARE Conference, 2006 Adelaide. Retrieved May 19, 2011 from http://www.aare.edu.au/06pap/abs06.htm

Kennewell, S., \& Beauchamp, G. (2007). The features of interactive whiteboards and their influence on learning. Learning, Media and Technology, 32, 227-241.

Kennewell, S., Tanner, H., Jones, S., \& Beauchamp, G. (2008). Analysing the use of interactive technology to implement interactive teaching. Journal of Computer Assisted Learning, 24, 61-73.

Knight, P., Pennant, J., \& Piggott, J. (2004). What does it mean to 'use the interactive whiteboard' in the daily mathematics lesson? Micromath, 20, 14-16.

Mayer, R. E. (2001). Multimedia learning. Cambridge: Cambridge University Press.

Mayer, R. E., \& Moreno, R. (2003). Nine ways to reduce cognitive load in multimedia learning. Educational Psychologist, 38, 43-52.

Moreno, R., \& Mayer, R. E. (2007). Interactive multimodal learning environments. Special Issue on Interactive Learning Environments: Contemporary Issues and Trends. Educational Psychology Review, 19, 309-326.

Shenton, A., \& Pagett, L. (2007). From 'bored' to screen: The use of the interactive whiteboard for literacy in six primary classrooms in England. Literacy (United Kingdom Literacy Association Journal), 41, 129-136.

Simpson, K. P. (2006). The effectiveness of cognitive flexibility hypertext in promoting active learning pedagogy: A multiple-case study. DAEd Thesis. George Mason University, Virginia.

Smith, F., Hardman, F., \& Higgins, S. (2006). The impact of interactive whiteboards on teacher-pupil interaction in the national literacy and numeracy strategies. British Educational Research Journal, 32, 443457.

Spiro, R. J., Coulson, R. L., Feltovich, P. J., \& Anderson, D. K. (1988). Cognitive Flexibility Theory: Advanced knowledge acquisition in ill-structured domains. Cognitive Science Society (pp. 375-383). Hillsdale, NJ: Erlbaum.

Spiro, R.J., Feltovich, P.J., Jacobson, M.J., \& Coulson, R.L. (1992). Cognitive flexibility, constructivism and hypertext: Random access instruction for advanced knowledge acquisition in ill-structured domains. In T. Duffy \& D. Jonassen (Eds.), Constructivism and the technology of instruction (pp. 57-75). Hillsdale, NJ: Erlbaum.

Spiro, R. J., Feltovich, P. J., Jacobson, M. J., \& Coulson, R. L. (1995). Cognitive flexibility, constructivism, and hypertext: Random access instruction for advanced knowledge acquisition in ill-structured domains. In L. P. Steffe \& J. E. Gale (Eds.), Constructivism in education (pp. 85-107). Hillsdale, NJ: Lawrence Erlbaum Associates, Inc.

Spiro, R. J., \& Jehng, J.-C. (1990). Cognitive flexibility and hypertext: Theory and technology for the nonlinear and multidimensional transversal complex subject matter. In D. Nix \& R. J. Spiro (Eds.), Cognition, education, and multimedia: Exploring ideas in high technology (pp. 163-205). Hillsdale, NJ: L. Erlbaum.

Vygotsky, L. S. (1978). Mind in society. Cambridge, MA: Harvard University Press.

Way, J., Lilley, E., Ruster, C., Johnco, S., Mauric, L., \& Ochs, L. (2009). Symposium: Interactive whiteboards and pedagogy in primary classrooms. Paper presented at the Annual Conference of Australian Association for Research in Education. Canberra, Australia. Retrieved May 19, 2011, from http://www.aare.edu.au/09pap/way091149.pdf

Wood, R., \& Ashfield, J. (2008). The use of the interactive whiteboard for creative teaching and learning in literacy and mathematics: A case study. British Journal of Educational Technology, 39, 84 - 96. 


\section{Biography}

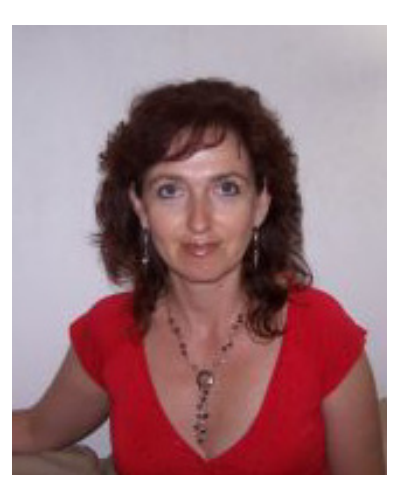

Dr. Ina Blau holds a PhD in E-Learning and CyberPsychology from the University of Haifa, Israel. She is a senior faculty in the Department of Education and Psychology at the Open University of Israel. In addition, she teaches in the Department of Information and Knowledge Management, Graduate School of Management, University of Haifa. Her research interests include social aspects of Internet use and ecommunication, online risks and safety, participation patterns, ecollaboration, as well as integration of innovative technologies in education system and organizations.

http://www.openu.ac.il/Personal_sites/ina-blau/ 